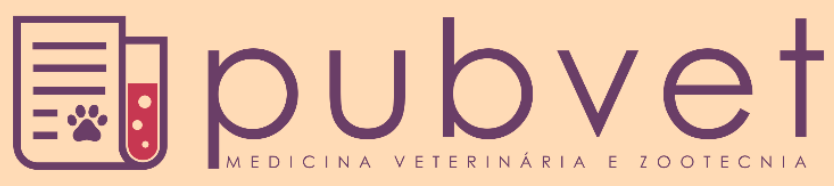

https://doi.org/10.31533/pubvet.v15n09a922.1-4

\title{
Linfoma ósseo primário em felino: Relato de caso
}

\author{
Bruno Roque ${ }^{\ominus}$, Daiane Paraguasú Fagundes ${ }^{\circ}$, Tayana Larissa Lemos ${ }^{3}{ }^{\circ}$, Vitória Fernandes Pires ${ }^{\circ}$ \\ ${ }^{I}$ Doutor em Oncologia Veterinária - AC Camargo Câncer Center, Professor do Instituto De Pós-graduação Veterinária Qualittas. Santos/SP. \\ ${ }^{2}$ Especialista em Oncologia Veterinária - Instituto De Pós-graduação Veterinária Qualittas, Médica Veterinária Pet Center PVH. Porto Velho/RO. \\ ${ }^{3}$ Aluna do Instituto De Pós-graduação Veterinária Qualittas. Patrocínio/MG \\ ${ }^{4}$ Graduanda do curso de Medicina Veterinária Universidade São Judas Tadeu. Santos/SP. \\ brunoroque.vetonco@gmail.com
}

Resumo. A incidência de lesões oncológicas tem aumentado nos últimos anos, sendo o linfoma a neoplasia mais comum em gatos na rotina clínica, acomete cerca de 50\% de todos os tumores hemolinfáticos nos gatos. Este aumento ocorre de forma multifatorial, sendo um dos principais a maior longevidade dos animais de companhia. Não se conhece a etiologia precisa do linfoma felino em muitos casos, entretanto, causas virais de linfoma felino são bem definidas, havendo infecções tanto pelo vírus da leucemia felina quanto pelo vírus da imunodeficiência felina. O linfoma consiste em uma neoplasia maligna de origem linfocitária, caracterizado pela proliferação clonal de linfócitos malignos, originando-se principalmente de órgãos linfoides, como a medula óssea, baço e linfonodos. Os linfócitos fazem parte do nosso sistema imune e distribuem-se por todo o corpo. O linfoma pode ser classificado como multicêntrico que possuem origem nos gânglios linfáticos, tímico, hepático, esplénico, gastrointestinal e os linfomas extra nodais linfoma cutâneo, nasal, renal e em sistema nervoso. Os sintomas mais comuns são a perda de peso e apetite e os sinais gastrointestinais: vómitos e diarreia.

Palavras-chave: Câncer, felinos, gatos, Linfoma, oncologia

\section{Feline primary bone lymphoma: A case report}

Abstract. The incidence of cancer lesions has increased in recent years, with lymphoma being the most common neoplasm in cats in the clinical routine, affecting about $50 \%$ of all hemolymphatic tumors in cats. This increase occurs in a multifactorial way, one of the main ones being the longevity of pet animals. The precise etiology of feline lymphoma is not known in many cases; however, viral causes of feline lymphoma are well defined, with infections by both feline leukemia virusand feline immunodeficiency virus. Lymphoma consists of a malignant neoplasm of lymphocytic origin, characterized by the clonal proliferation of malignant lymphocytes, originating mainly from lymphoid organs, such as bone marrow, spleen and lymph nodes. Lymphocytes are part of our immune system and are distributed throughout the body. Lymphoma can be classified as multicentric originating in the lymph nodes, thymic, hepatic, splenic, gastrointestinal and extra nodal lymphomas cutaneous, nasal, renal and nervous system lymphoma. The most common symptoms are weight loss and appetite and gastrointestinal signs: vomiting and diarrhea.

Key words: Cancer, felines, cats, Lymphoma, oncology.

\section{Linfoma óseo primario felino: Reporte de un caso}

Resumen. La incidencia de lesiones cancerosas ha aumentado en los últimos años, siendo el linfoma la neoplasia más común en gatos en la rutina clínica, afectando aproximadamente al $50 \%$ de todos los tumores hemolinfáticos en gatos. Este aumento se produce de forma multifactorial, siendo una de las principales la mayor longevidad de los 
animales de compañía. La etiología precisa del linfoma felino no se conoce en muchos casos, sin embargo, las causas virales del linfoma felino están bien definidas, con infecciones tanto por el virus de la leucemia felina como por el virus de la inmunodeficiencia felina. El linfoma consiste en una neoplasia maligna de origen linfocítico, caracterizada por la proliferación clonal de linfocitos malignos, originados principalmente de órganos linfoides, como médula ósea, bazo y ganglios linfáticos. Los linfocitos son parte de nuestro sistema inmunológico y se distribuyen por todo el cuerpo. El linfoma se puede clasificar como multicéntrico con origen en los ganglios linfáticos, linfomas tímicos, hepáticos, esplénicos, gastrointestinales y extraganglionares cutáneos, linfomas nasales, renales y del sistema nervioso. Los síntomas más comunes son pérdida de peso y apetito y signos gastrointestinales: vómitos y diarrea.

Palabras claves: Cáncer, felinos, gatos, linfoma, oncología

\section{Introdução}

Os tumores hematopoiéticos são as neoplasias mais comuns em gatos, eles representam 1/3 das doenças malignas diagnosticadas, e 90\% dos tumores hematopoiéticos diagnosticados na espécie são linfomas (Wilson, 2008). No Brasil, segundo relatos publicados por Serviços de Patologia e de Oncologia Veterinária das universidades nacionais, os tumores hematopoiéticos são o terceiro tipo de neoplasia mais comum. No caso do linfoma em felinos é possível observar uma incidência anual de 200 novos casos para cada 100.000 (Daleck et al., 2016); enquanto em humanos, segundo a estimativa de 2020 realizada pelo Instituto Nacional de Câncer José Alencar Gomes da Silva (INCA) há uma estimativa de 6,31 casos novos a cada 100 mil homens e de 5,07 para cada 100 mil mulheres no caso de linfoma não Hodgkin.

O linfoma ósseo primário é um tumor intramedular raro e caracteriza-se por linfomas localizados em único sítio ósseo com ou sem envolvimento de linfonodo regional, ou em múltiplos sítios ósseos sem envolvimento visceral ou de linfonodo regional (Campbell et al., 2003; Ribeiro et al., 2017). O linfossarcoma é considerado uma doença multifatorial, com várias causas descritas, principalmente relacionadas com componentes genéticos, exposição a agentes químicos, ao tabaco e aos retrovírus, como FIV e FeLV (Bertone et al., 2002; Daleck et al., 2016; Shelton et al., 1990).

Os animais mais afetados têm lesões múltiplas e discretas envolvendo vários ossos do esqueleto apendicular e axial. Em ossos longos, as lesões podem envolver regiões diafisárias ou metafisárias. As fraturas patológicas são comumente associadas às lesões líticas e déficits neurológicos, incluindo ataxia e paraparesia, que foram associados a lesões vertebrais. A hipercalcemia é relatada em alguns casos.

Os diagnósticos diferenciais da doença incluem: mieloma múltiplo, osteomielite e doenças osteometabólicas (Langley-Hobbs et al., 1997). A confirmação do linfoma ósseo primário é feita através do exame histopatológico ou por citologia aspirativa por agulha fina das lesões líticas (Meuten, 2016; Valli et al., 2017). Uma vez estabelecido o diagnóstico, deve-se determinar o estádio clínico de acordo com a extensão e a gravidade da doença em que o paciente se encontra. Nos felinos, os estádios III, IV e V são os mais frequentes, uma vez que os estádios iniciais dificilmente são identificados pelos proprietários. O estadiamento clínico é de fundamental importância para a definição do prognóstico e a escolha da terapia (Daleck et al., 2016).

O tratamento pode ser feito por radioterapia isoladamente ou em combinação com quimioterapia sistêmica, e pode alcançar remissão em meses ou ano (Langley-Hobbs et al., 1997). O tempo médio de sobrevida de gatos com linfoma é de aproximadamente oito meses. A resposta inicial à quimioterapia é o fator prognóstico mais seguro nessa espécie. Aqueles que alcançam remissão completa apresentam tempo de sobrevida significativamente maior em relação aos que apresentam remissão parcial. A localização anatômica do linfoma também representa um indicador prognóstico relevante. $\mathrm{O}$ prognóstico é desfavorável para os pacientes soropositivos para FIV e FeLV (Daleck et al., 2016).

\section{Relato de caso e discussão}

Foi atendido em um hospital particular em Santos, São Paulo um felino, filhote com 10 meses de idade, sem raça definida, apresentando sintomas de dor, normohidratado, temperatura 38,3. O 
proprietário relata claudicação de membro posterior esquerdo e aumento de volume na região do membro. Foram solicitados os exames laboratoriais para estadiamento, tais como hemograma e bioquímicas. Hemograma com leucopenia acentuada 3,8/mm3.

O animal possui também radiografia (Figuras 1) nas quais observa-se lesão mista em região de epífise, metáfise e diáfise proximal, apresentando lise óssea permeativa com áreas focais de esclerose, e reação periosteal ativa e irregular em camada cortical cranial e zona de transição indistinta entre osso normal e anormal.

Foram solicitamos exames de ultrassonografia abdominal e Radiografia de tórax, ambos sem alterações clínicas.

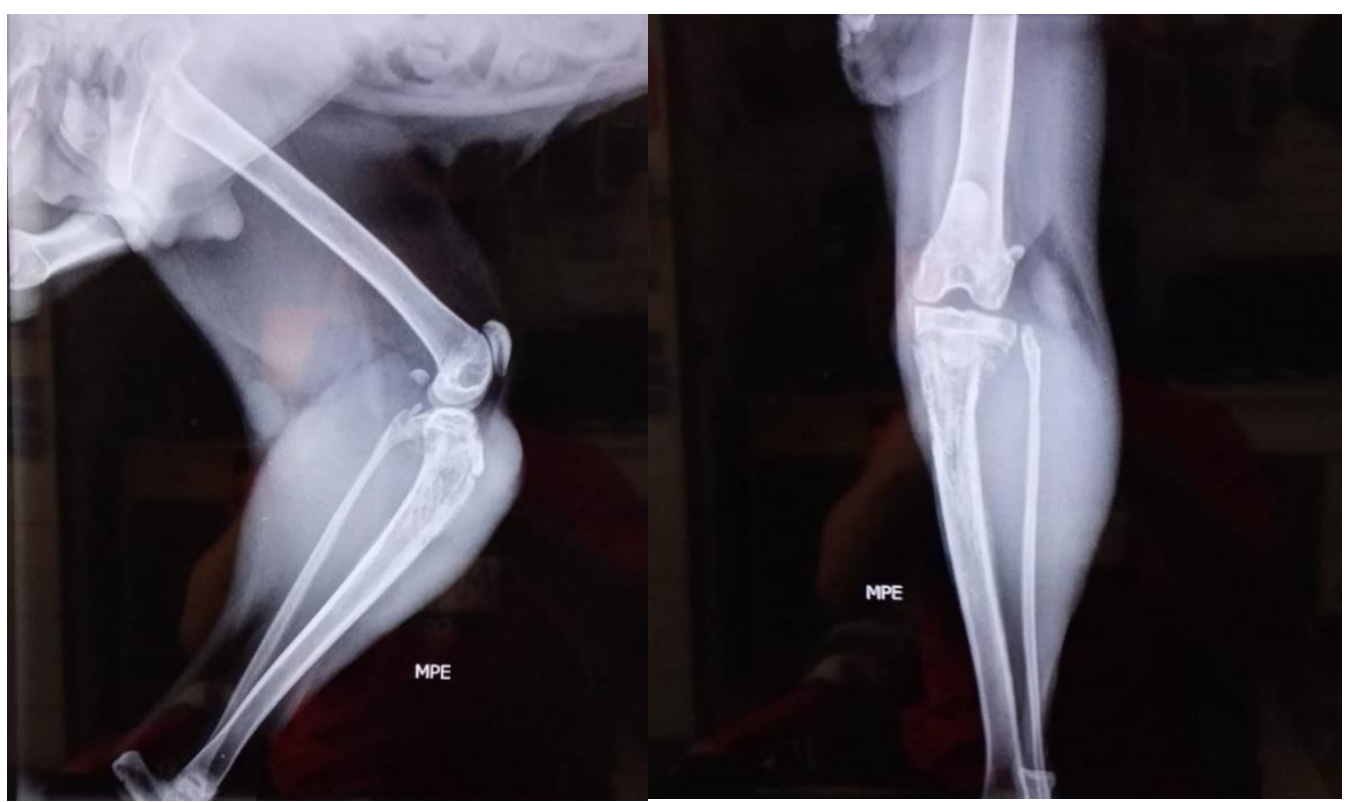

Figura 1. Radiografia de membro posterior esquerdo

Para o diagnóstico e controle de dor foi realizado o procedimento cirúrgico de amputação de membro e mandado o material para avaliação histopatológica. No exame histopatológico constatou-se presença população monomórfica de grandes linfócitos, apresentando cinco mitoses por campo, caracterizando linfoma de grandes células.

De acordo com Withrow et al. (2020), tumores ósseos primários em felinos são raros, onde 70\% a $80 \%$ destes são caracterizados como osteossarcoma, se tornando assim, o tumor ósseo primário mais comum em gatos. Já o tipo de linfoma mais diagnosticado em felinos é o gastrointestinal (Waite et al., 2013). O linfoma ósseo primário é pouco citado na literatura. Sabe-se que os vírus da leucemia felina (FelV) e da imunodeficiência felina (FiV) predispõe ao aparecimento de linfoma, independentemente, de sua localização (Daleck et al., 2016), apesar de já ser relatado um declínio na associação do vírus da leucemia felina em pacientes que apresentam linfomas (Withrow et al., 2013). Segundo Ettinger (2003), o animal negativo para o FelV tem um melhor prognóstico. Nesse caso o animal era testado e negativo para FelV.

Como citado por Vascellari et al. (2007), o linfoma ósseo primário pode ocorrer em cães e humanos, mas é mais comum que o envolvimento ósseo seja associado ao linfoma multicêntrico em cães, gatos e bovinos. Sendo esta informação oposta do caso relatado, já que o paciente não apresentava alterações condizentes com linfoma multicêntrico.

Quando o linfoma extranodal está localizado em um único sitio anatômico, a terapia local é apropriada (Moore, 2013), com isso foi realizada a intervenção cirúrgica, fazendo assim a amputação do membro.

Em associação ao procedimento cirúrgico, também foi definido tratamento sistêmico, elegendo o protocolo quimioterápico $\mathrm{CHOP}$, este permite tempo de sobrevida e remissão mais longos (Daleck et al., 2016). O protocolo escolhido é apropriado para gatos que apresentam linfomas de grandes células, 
envolvendo qualquer sítio anatômico (Withrow et al., 2013). O protocolo quimioterápico foi finalizado com dezesseis sessões em dezenove semanas e o paciente se encontra remissão.

\section{Referências bibliográficas}

Bertone, E. R., Snyder, L. A., \& Moore, A. S. (2002). Environmental tobacco smoke and risk of malignant lymphoma in pet cats. American Journal of Epidemiology, 156(3), 268-273. https://doi.org/10.1093/aje/kwf044..

Campbell, S. E., Filzen, T. W., Bezzant, S. M., Beall, D. P., Burton, M. P., Sanders, T. G., \& Parsons, T. W. (2003). Primary periosteal lymphoma: an unusual presentation of non-Hodgkin's lymphoma with radiographic, MR imaging, and pathologic correlation. Skeletal Radiology, 32(4), 231-235. https://doi.org/10.1007/s00256-002-0610-0.

Daleck, C. R., Fonseca, C. S., \& Canola, J. C. (2016). Oncologia em cães e gatos. Roca.

Ettinger, S. N. (2003). Principles of treatment for canine lymphoma. Clinical Techniques in Small Animal Practice, 18(2), 92-97.

Langley-Hobbs, S. J., Carmichael, S., Lamb, C. R., Bjornson, A. P., \& Day, M. J. (1997). Polyostotic lymphoma in a young dog: a case report and literature review. The Journal of Small Animal Practice, 38(9), 412-416. https://doi.org/10.1111/j.1748-5827.1997.tb03495.x.

Meuten, D. J. (2016). Tumors in domestic animals. John Wiley \& Sons.

Moore, A. (2013). Extranodal lymphoma in the cat: prognostic factors and treatment options. Journal of Feline Medicine and Surgery, 15(5), 379-390. https://doi.org/10.1177/1098612X13483236.

Ribeiro, R. C. S., Aleixo, G. A. S., \& Andrade, L. S. S. (2017). Linfoma canino: revisão de literatura. Medicina Veterinária, 9(1-4), 10-19.

Shelton, G. H., Grant, C. K., Cotter, S. M., Gardner, M. B., Hardy Jr, W. D., \& DiGiacomo, R. F. (1990). Feline immunodeficiency virus and feline leukemia virus infections and their relationships to lymphoid malignancies in cats: a retrospective study (1968-1988). Journal of Acquired Immune Deficiency Syndromes, 3(6), 623-630.

Valli, V. E., Bienzle, D., Meuten, D. J., \& Linder, K. E. (2017). Tumors of the hemolymphatic system. Tumors in Domestic Animals, 5, 203-321. https://doi.org/10.1002/9781119181200.ch7.

Vascellari, M., Tasca, S., Furlanello, T., Carli, E., Patron, C., Mutinelli, F., \& Caldin, M. (2007). Vertebral polyostotic lymphoma in a young dog. Journal of Veterinary Diagnostic Investigation, 19(2), 205-208. https://doi.org/10.1177/104063870701900214.

Waite, A. H. K., Jackson, K., Gregor, T. P., \& Krick, E. L. (2013). Lymphoma in cats treated with a weekly cyclophosphamide-, vincristine-, and prednisone-based protocol: 114 cases (1998-2008). Journal of the American Veterinary Medical Association, 242(8), 1104-1109. https://doi.org/10.2460/javma.242.8.1104.

Wilson, H. M. 2008. (2008). Feline alimentary lymphoma: Demystifying the enigma. Topics in Companion Animal Medicine, 23, 177-184.

Withrow, S. J., Page, R., \& Vail, D. M. (2013). Small Animal Clinical Oncology-E-Book. Elsevier Health Sciences.

Withrow, S. J., Page, R., \& Vail, D. M. (2020). Small animal clinical oncology. Elsevier Health Sciences. https://doi.org/10.1201/9781315381855.

Histórico do artigo:

Recebido: 20 de maio de 2021

Aprovado: 26 de junho de 2021
Licenciamento: Este artigo é publicado na modalidade Acesso Aberto sob a licença Creative Commons Atribuição 4.0 (CC-BY 4.0), a qual permite uso irrestrito, distribuição, reprodução em qualquer meio, desde que o autor e a fonte sejam devidamente creditados. 